\title{
Exploitation of the solid waste of porfiritis in pozzolanic cements
}

\author{
G. Batis, P. Pantazopoulou \& O. Stavropoulou \\ Department of Chemical Engineering, \\ National Technical University of Athens, Greece
}

\begin{abstract}
The objective of this paper is to investigate the possibility of introducing a natural pozzolan named porfiritis, a natural waste product from the gold mines located in N.E. Chalkidiki Greece, as a supplementary cementing material. Blended cement was produced by replacing PC with $20 \% \mathrm{w} / \mathrm{w}$ porfiritis for the evaluation of the pozzolanic cement properties. Reinforced mortar specimens were either partially immersed in $3.5 \% \mathrm{w} / \mathrm{w} \mathrm{NaCl}$ solution or exposed to atmospheric conditions, for a period of 6 months. The experimental methods used were: corrosion potential, corrosion rate by the Linear Polarization method, mass loss, carbonation depth and compressive strength. Based on the results of this study, it is concluded that the use of the porfiritic deposit as a blended cement constituent improves the corrosion behaviour of the mortar specimens, while no serious detrimental effect on the mechanical behaviour of the concrete is detected.
\end{abstract}

Keywords: porfiritis, pozzolanic cements, chlorides corrosion, carbonation.

\section{Introduction}

The blended cement industry is a relatively new and rapidly growing field. The literature on blended cements is extensive, as measurements at laboratory and pilot-plant scale have been carried out over a period of about 50 years. Blended cements provide specific technical advantages in comparison with ordinary Portland cement, with regard to durability in various corrosion environments. One of the most common materials classified as cementitious is natural pozzolans, natural material containing silica in a reactive form [1-3]. 
In this work, a natural pozzolan named porfiritis is investigated for its possible use in concrete. Porfiritis is actually a natural waste product from N.E. Chalkidiki, Greece. The gold extraction procedure in the mines located there involves the extraction of porfiritic deposits with rich gold content. It is important to note that for every tone of the mineral deposit unearthed, only 1-2 grams are going to be tapped, while the rest of the deposit remains unexploited. The possible exploitation of this natural material is considered a step forward in the general attempt for sustainable development in our times [4]. Nevertheless, there are no laboratory scale measurements on the suitability of the reuse of this material as a blended cement constituent.

Granulated porfiritis mainly consists of calcium, silicate and alumina oxides. According to the relative EN 450-1 standard, the determined reactive silica of the material is found equal to 25.5 , meaning that the material is appropriate for the incorporation in concrete. Consequently, the study is further focused on the effect of the addition of porfiritis on the durability and mechanical behaviour of the blended cement.

\section{Experimental}

\subsection{Materials and preparation of mortar specimens}

For the control of the durability related properties considered, blended cement was produced by replacing PC with $20 \% \mathrm{w} / \mathrm{w}$ porfiritis (PORF20). The mortar mixture of $\mathrm{PC}$ with the natural pozzolan was tested and compared with specimens with pure PC (REF). The mix proportions cement / sand / water were kept constant and equal to 1/3/0.5. Reinforcing steel bars of steel type Tempcore S500s, Greek sand and tap water were also used. The chemical composition of Portland cement (PC: $\mathrm{I} / 42.5 \mathrm{~N}$ ), porfiritis and steel used in casting the reinforced specimens are given in Tables 1-2.

Table 1: $\quad$ Chemical composition of $\mathrm{PC}$ and porfiritis $(\% \mathrm{w} / \mathrm{w})$.

\begin{tabular}{|c|c|c|c|c|c|c|c|c|c|c|}
\hline & $\mathrm{SiO}_{2}$ & $\mathrm{Al}_{2} \mathrm{O}_{3}$ & $\mathrm{Fe}_{2} \mathrm{O}_{3}$ & $\mathrm{CaO}$ & $\mathrm{MgO}$ & $\mathrm{K}_{2} \mathrm{O}$ & $\mathrm{Na}_{2} \mathrm{O}$ & $\mathrm{SO}_{3}$ & $\mathrm{CaO}_{(\mathrm{f})}$ & $\mathrm{LOI}$ \\
\hline $\mathrm{OPC}$ & 20.67 & 4.99 & 3.18 & 63.60 & 2.73 & 0.37 & 0.29 & 2.41 & 2.41 & 2.52 \\
\hline Porfiritis & 34.34 & 10.37 & 2.44 & 41.30 & 6.90 & 0.32 & 0.38 & 0.12 & - & 0.09 \\
\hline
\end{tabular}

Table 2: Chemical composition of steel $(\% \mathrm{w} / \mathrm{w})$.

\begin{tabular}{|c|c|c|c|c|c|c|c|c|c|}
\hline $\mathrm{C}$ & $\mathrm{Mn}$ & $\mathrm{S}$ & $\mathrm{P}$ & $\mathrm{Si}$ & $\mathrm{Ni}$ & $\mathrm{Cr}$ & $\mathrm{Cu}$ & $\mathrm{V}$ & $\mathrm{Mo}$ \\
\hline 0.18 & 0.99 & 0.047 & 0.023 & 0.15 & 0.09 & 0.09 & 0.21 & 0.02 & 0.021 \\
\hline
\end{tabular}

Cylindrical mortar specimens with axially embedded steel bars were cast on the basis of previously established standards. Dimensions of the reinforced mortar specimens are presented in Figure 1. Specimens were stored at ambient 
conditions for $24 \mathrm{~h}$ and after been demoulded they were cured in tap water for another $24 \mathrm{~h}$. The specimens were finally covered with epoxy glue Araldite ${ }^{\circledR}$, as shown in Figure1. Reference specimens as well as porfiritis specimens were then exposed to the two corrosive environments: they were either partially immersed up to $20 \mathrm{~mm}$ height of the mortar cylinder in artificial seawater $(3.5 \% \mathrm{w} / \mathrm{w} \mathrm{NaCl}$ solution), or exposed in atmospheric conditions, for a total period of 6 months.

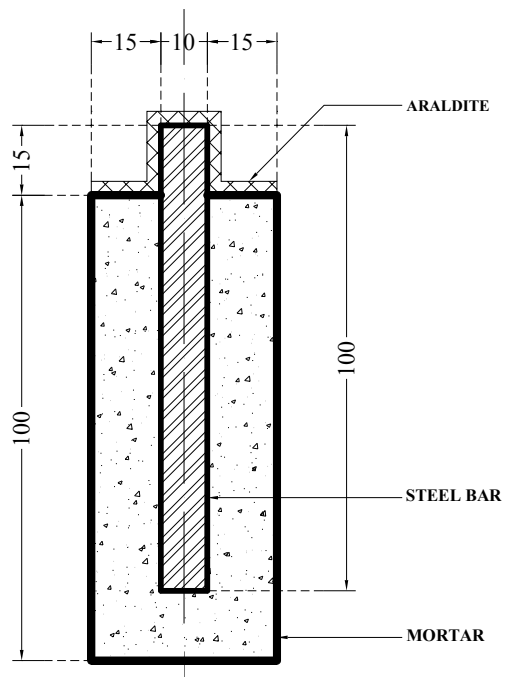

Figure 1: $\quad$ Mortar specimen (mm).

For the compressive strength measurements, $150 \mathrm{~mm}$ cube specimens were prepared of PC (control specimens, REF) and PC with the $20 \% \mathrm{w} / \mathrm{w}$ cement replacement of porfiritis (PORF20). The concrete mixing composition is presented in Table 3. The mixing procedure and the preparation of the concrete specimens were conformed to the European Standard EN 196. The vibration time was $2 \mathrm{~min}$ in all. The procedure included demoulding the cubes $24 \mathrm{~h}$ after casting and storing them in a humid chamber (average temperature $20^{\circ} \mathrm{C}$ and $\mathrm{RH}>98 \%$, respectively) until the age of testing.

Table 3: $\quad$ Concrete mixture proportions $\left(\mathrm{kg} / \mathrm{m}^{3}\right)$.

\begin{tabular}{|l|r|r|r|r|r|r|}
\hline & OPC & Porfiritis & $\begin{array}{r}\text { Fine } \\
\text { aggregate }\end{array}$ & $\begin{array}{r}\text { Coarse } \\
\text { aggregate }\end{array}$ & Sand & Water \\
\hline REF & 280 & - & 480 & 480 & 960 & 180 \\
\hline PORF20 & 224 & 56 & 480 & 480 & 960 & 180 \\
\hline
\end{tabular}

\subsection{Techniques}

The experimental methods used for the testing of the performance of reinforced control and blended mortar specimens in the corrosive environment of $3.5 \% \mathrm{w} / \mathrm{w}$ $\mathrm{NaCl}$ solution were: measurement of the corrosion potential, determination of the 
corrosion rate by the Linear Polarization method, mass loss and carbonation depth.

The half-cell potential of the rebars was measured versus immersion time using a saturated calomel electrode (SCE) as a reference electrode, according to ASTM C876-87. The results present average values of 4 specimens of each type.

At predetermined immersion times specimens of the two categories were removed from the corrosive environment in order to estimate the corrosion rate of the reinforcing steel according to mass loss measurements. Corrosion products were removed from the steel surface as described in ISO/DIS 8407 standard. From the difference between the initial and the final mass, the mass loss was found on 4 specimens of each category, and the averages of these 4 values are reported.

At the same predetermined exposure time intervals the corrosion rate of the rebars was also assessed by running each month a potentiodynamic linear polarization scan on 4 specimens of each category, using a 263A EG\&G model potentiostat / galvanostat. The experimental procedure has been described in previous work [5].

The phenolphthalein method (RILEM CPC-18) applied on a longitudinal section of each specimen was used for the estimation of the carbonation depth time development of the mortars.

Mass loss and carbonation depth measurements were also carried out in specimens exposed to atmospheric conditions in order to examine their durability behaviour characteristics.

The compressive strength test procedure followed EN196-1 standard. The results for the two concrete types represent an average value of three tests on the ages of 7 and 28 days.

\section{Results and discussion}

\subsection{NaCl solution environment}

The corrosion of steel is usually detected by indirect methods based on the corrosion potential of the steel bars. The corrosion tendency of the reinforcing steel bars is evaluated by means of the half-cell potential measurements versus the exposure time in the corrosive environment. Plots of this evolution for the two mortar categories are given in Figure 2.

Figure 2 demonstrates that the monitored corrosion potentials for the two specimen categories exhibit comparable values during the exposure time of 6 months. An expected decay of Ecor to more electronegative values during the first 130 days of exposure is observed for all examined specimens. Thereafter, over longer times of immersion, the average potentials appear to reach a constant Ecor value, about $-400 \mathrm{mV}$. It should be noticed that in the case of specimens with $20 \% \mathrm{w} / \mathrm{w}$ porfiritis a steeper decay is monitored during the first 130 days, followed by a tendency for stabilization to a slightly higher plateau value. Nevertheless, according to the plot, the differences in the development of the potential are not pronounced, and as a result, a qualitative prediction regarding differences in the corrosion performance of the specimens cannot be supported. 


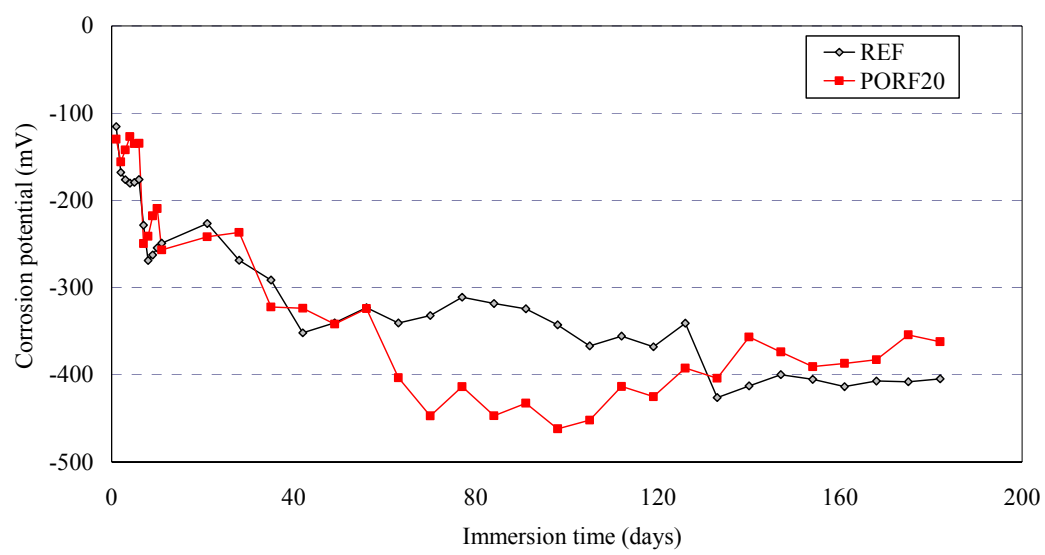

Figure 2: Evolution of the corrosion potential vs. immersion time in $3.5 \%$ w/w $\mathrm{NaCl}$ solution.

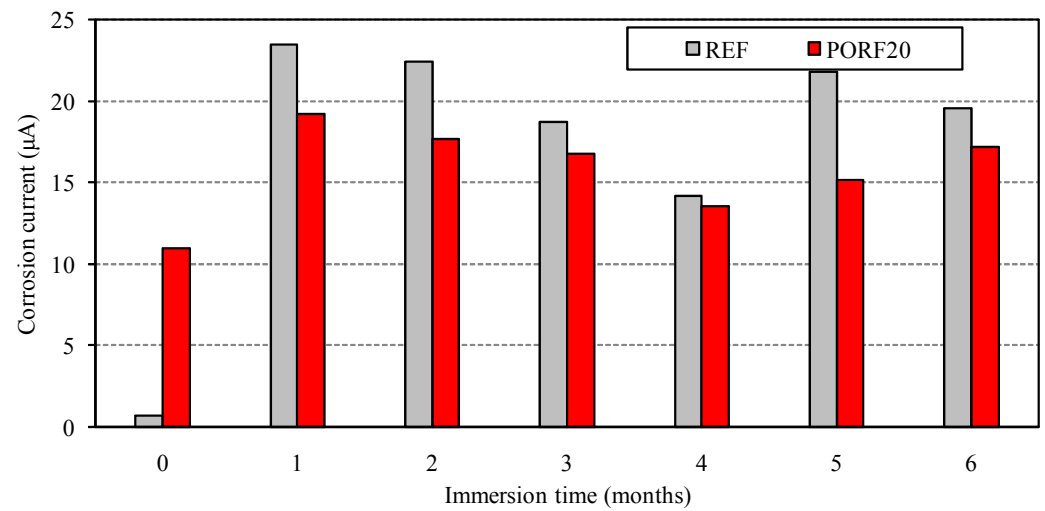

Figure 3: Corrosion current of mortar specimens immersed in $3.5 \% \mathrm{w} / \mathrm{w}$ $\mathrm{NaCl}$ solution.

For a further investigation of the corrosion rate of the reinforcing steel bars in the mortar specimens, Linear Polarization method tests were carried out every month for a total period of 6 months. Figure 3 presents the average corrosion current $(\mu \mathrm{A})$ monitored for the two types of specimens. A fluctuation of the measured current is observed, although current is found to increase with increased time of immersion in the $\mathrm{NaCl}$ solution from 0 to 6 months. Control specimens present significantly higher corrosion current values than the porfiritis specimens after the first month of immersion in the corrosive environment. This implies an increase in the electrochemical activity of the system that can be attributed to the increased corrosion of the steel rebars. In comparative terms, control specimens exhibit approximately $12 \%$ higher corrosion current values after 6 months of immersion. On the other hand, the hydration of blended 
cements is known to be slower and consequently their porosity is greater than that of Portland cements.

A further verification of the above electrochemical measurements was performed through mass loss tests also carried out every month. It must be emphasized that mass loss measurements versus the exposure time provide the possibility for a rather more correct prediction of the corrosion rate of the reinforcing steel than the previous methods. The results of the mass loss measurements versus immersion time are given in Figure 4.

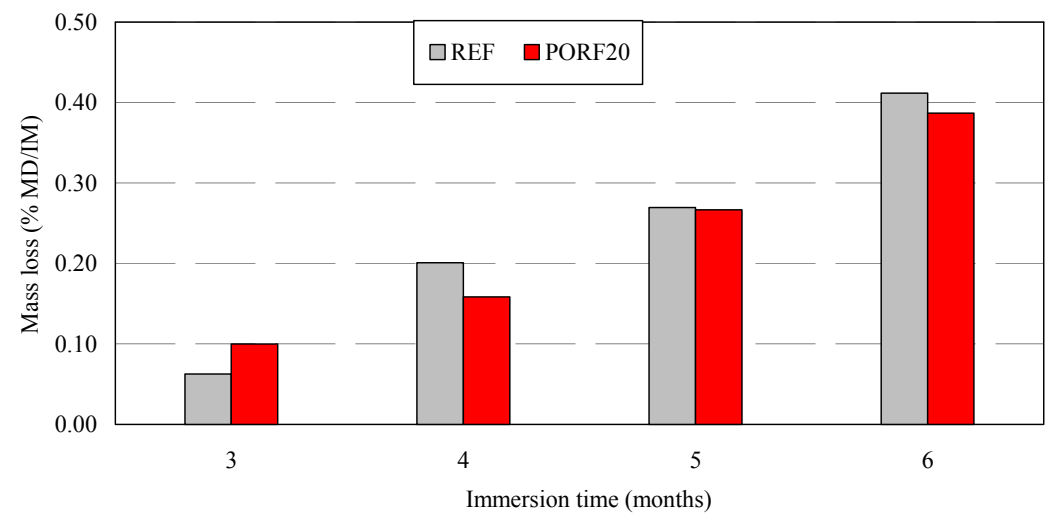

Figure 4: Mass loss of mortar specimens immersed in 3.5\% w/w $\mathrm{NaCl}$ solution.

According to this figure, in both types of specimens, there is a normal increase in the mass loss with the immersion time. It can be observed that control specimens present higher percentage mass loss after remaining 4, 5 or 6 months in the corrosive environment. Conversely, specimens with porfiritis appeared more vulnerable to corrosion during the first 3 months, resulting in higher mass loss of about $59 \%$. When compared with the blended cement specimens, control specimens exhibit an average $6 \%$ higher mass loss value after 6 months of immersion in the $3.5 \% \mathrm{w} / \mathrm{w} \mathrm{NaCl}$ solution. The above results correlate well with the electrochemical measurements presented above, where improved anticorrosive properties were predicted after the first 3 months of exposure.

The carbonation area measured in a longitudinal section of broken specimens partially immersed in $\mathrm{NaCl}$ solution is presented in Figure 5. It is well established that carbonation caused by atmospheric $\mathrm{CO}_{2}$ affects only the waterfree part of the specimens, and therefore, the measured values are not high.

Considering the results of all the methods applied in the case of the partial $\mathrm{NaCl}$ immersion, a better performance of blended specimens in corrosion resistance is concluded, especially after long exposure times (over 3 months). As stated in the literature [6] pozzolanic cements have a protective effect on corrosion, when chloride ions are present. The gain in durability, as a result of porfiritis inclusion in the mortar, is attributed to its beneficial influence on the 
concrete permeability, although this is not always obvious in early ages, as well as to the blended cements increased capacity to bind chlorides to their hydration products $[7,8]$.

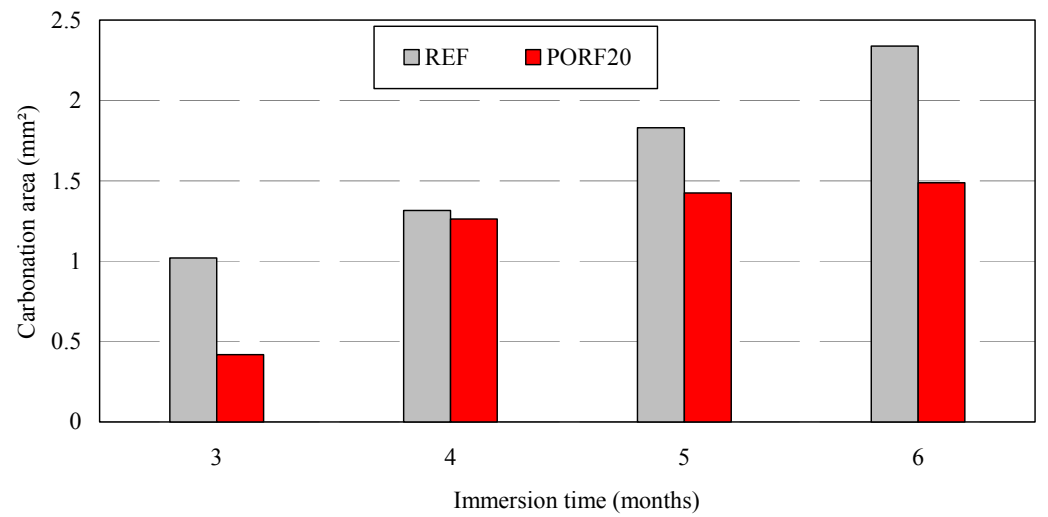

Figure 5: Carbonation area of mortar specimens immersed in $3.5 \% \mathrm{w} / \mathrm{w}$ $\mathrm{NaCl}$ solution.

\subsection{Durability in atmospheric condition}

Reference OPC specimens and mortar specimens with porfiritis $20 \% \mathrm{w} / \mathrm{w}$ replacement were exposed to atmospheric conditions for a total period of six months. Figure 6 presents the average mass loss measurements versus exposure time for the two mortar types. The results indicate that the blended cement specimens exhibited approximately $13 \%$ lower corrosion values after remaining in the corrosive environment for 5 or 6 months. However, as in the case of partial immersion in the $\mathrm{NaCl}$ solution and regarding resistance to corrosion in the case of short-term outdoor exposure (3 months), the results are not favorable.

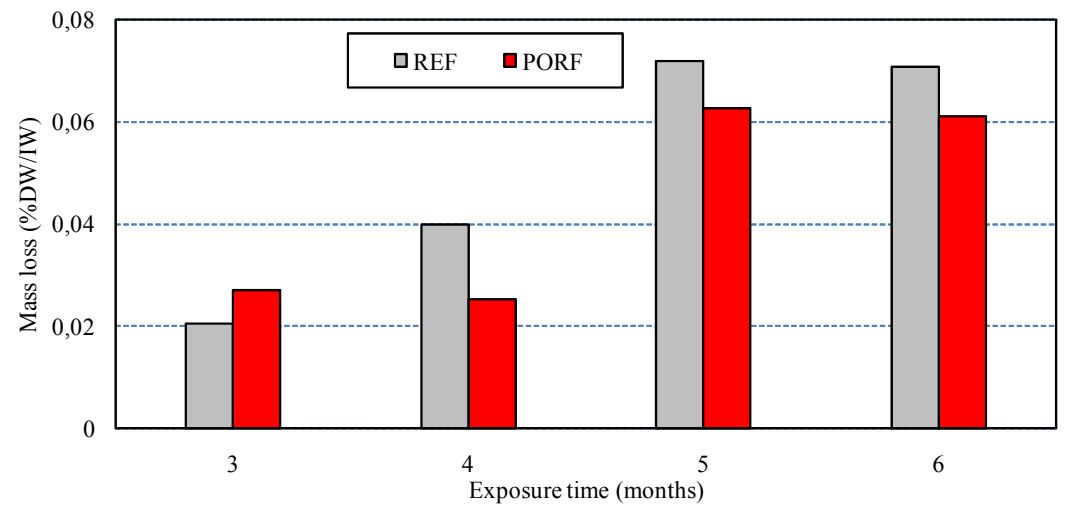

Figure 6: Mass loss of mortar specimens exposed to atmospheric conditions. 
Carbonation depth is probably the most important characteristic from the standpoint of durability in atmospheric conditions. The carbonation depth of mortar containing porfiritis as partial cement replacement in comparison to that of the conventional OPC mortar is presented in Figure 7. It can be seen that carbonation depth increases with increased exposure time. Particularly, after 6 months of exposure in the corrosive environment, specimens with porfiritis present carbonation depth values reduced by $10 \%$ in relation to that of the corresponding reference specimens.

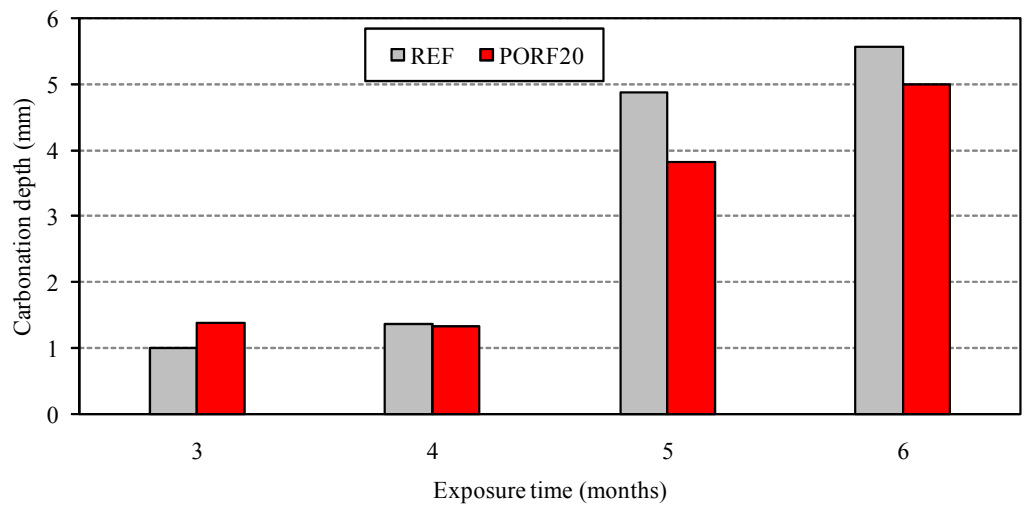

Figure 7: Carbonation depth of mortar specimens exposed to atmospheric conditions.

On the contrary, the addition of porfiritis does not significantly alter the measured carbonation in shorter exposure periods, while after 3 months of exposure, carbonation of the blended cement is by $37.5 \%$ increased. The above results are in agreement with the mass loss measurements presented above. In general, the use of pozzolanic admixtures influences the porosity and the permeability of the cement paste, and consequently the concrete performance regarding carbonation. On the other hand, according to literature [9], pozzolanic cements suffer from carbonation earlier than OPC cements. The present experimental results confirm the above remarks.

\subsection{Compressive strength}

Results from the compressive tests at 7 and 28 days of hydration are plotted in Figure 8. It is observed that the partial cement replacement results in an approximately $20 \%$ reduction of the compressive strength at 7 days. A significant improvement was observed at 28 days, as the deviation becomes less apparent (14.5\%). Furthermore, according to the Figure 8, a higher strength development is registered in the case of the blended cement. It is concluded that the incorporation of porfiritis resulted in a slight reduction in the measured compressive strength. The results are in accordance with other experimental studies published elsewhere [7], where the presence of pozzolanic admixtures is reported to no longer influence the strength after the age of 1 year. 


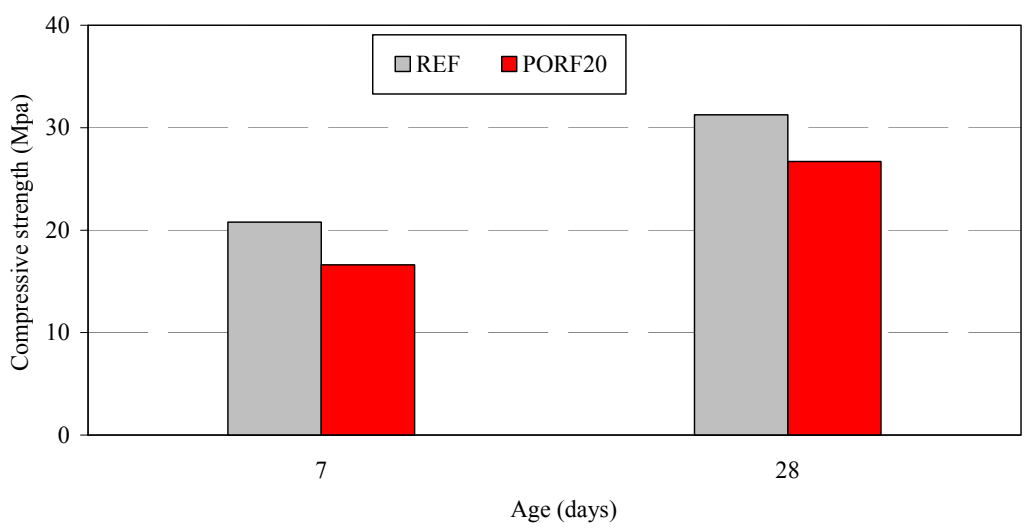

Figure 8: Compressive strength measurements.

\section{Conclusions}

In this study an investigation has been carried out for the evaluation of the influence of cement replacement by a pozzolanic material named porfiritis, extracted from the gold mines in N.E. Chalkidiki, Greece. The research was mainly devoted to the durability related characteristics of the produced blended cement, as well as the mechanical properties of the produced concrete. It is concluded that the use of porfiritis as a $20 \% \mathrm{w} / \mathrm{w}$ cement replacement improves the corrosion behavior of mortar specimens, with no significant consequence on the compressive strength. The experimental investigation of the present paper yielded the following conclusions.

- The protection offered by the addition of porfiritis, calculated from the mass loss measurements after 6 months of immersion in $3.5 \% \mathrm{w} / \mathrm{w} \mathrm{NaCl}$ solution, is equal to $6 \%$.

- The corresponding percentage in the case of atmospheric conditions is equal to $13 \%$.

- The partial cement replacement by porfiritis resulted in a $14.5 \%$ reduction in the compressive strength at 28 days.

The above results confirm that there is possibility for the use of porfiritis as a cement replacement, in a way to resolve the environmental concern of its disposal, though further research is needed before definite conclusions can be drawn.

\section{References}

[1] Mehta, P.K. \& Monteiro, P., Concrete Microstructure, Properties \& Materials, McGraw-Hill, New York, 2005. 
[2] Manso, J.M., Polanco, J.A., Losanez, M. \& Gonzalez, J.J., Durability of concrete made with EAF slag as aggregate, Cement \& Concrete Composites, 28, pp. 528-534, 2006.

[3] Basheer, P.A.M., Gilleece, P.R.V, Long, A.E. \& McCarter, W.J., Monitoring electrical Resistance of Concretes containing Alternative Cementitious Materials to Assess their Resistance to Chloride Penetration, Cement \& Concrete Composites, 24, pp. 437-449, 2002.

[4] Pioro, L.S. \& Pioro, I.L., Reprocessing of metallurgical slag into materials for the building industry, Waste Management, 24, pp. 371-379, 2004.

[5] Batis, G., Pantazopoulou, P., Tsivilis, S. \& Badogiannis, E., The effect of metakaolin on the corrosion behavior of cement mortars, Cement and Concrete Composites, 27(1), pp. 125-130, 2005.

[6] Kouloumbi, N., Batis, G. \& Malami, Ch., The anticorrosive effect of fly ash, slag and a Greek pozzolan in reinforced concrete, Cement and Concrete Composites, 16, pp. 253-260, 1994.

[7] Neville, A.M., Properties of Concrete, Addison Wesley Longman Limited, $4^{\text {th }}$ ed, England, 1996.

[8] Jau, W. \& Tsay, D., A Study of the Basic Engineering Properties of Slag Cement Concrete and its Resistance to Seawater Corrosion, Cement and Concrete Research, 28, pp. 1363-1371, 1998.

[9] Bakharev, T., Sanjayan, J., G. \& Cheng, Y., Resistance of Alkali-Activated Slag Concrete to Carbonation, Cement and Concrete Research, 31, pp. 1277-1283, 2001. 